MedieKultur | Journal of media and communication research | ISSN 1901-9726

Article - Theme section

\title{
Film archives and digital humanities \\ - an impossible match? \\ New job descriptions and the challenges of the digital era
}

\section{Adelheid Heftberger}

MedieKultur 2014, 57, 135-153

Published by SMID | Society of Media researchers In Denmark | www.smid.dk The online version of this text can be found open access at www.mediekultur.dk

This article seeks to prompt a re-evaluation of the film archive's role within the current digital humanities debate as a logical, yet underrated, partner. The article invokes Jeffrey Schnapp's and Todd Presner's plea from 2009 for digital humanities to create as its core aim a more democratic view of knowledge-producing institutions by including non-university research institutions as well as archives and museums. Archives, on the other hand, currently face the crucial challenge of how to digitise and present their collections online while struggling with rising related costs and having to redefine their mission as heritage keepers for often unique analogue material. The potential options for future collaboration between film archives and digital humanists as well as film scholars will also be discussed in this paper through an examination of the current situation.

\section{Introduction}

Archives, libraries and collecting institutions in general are undoubtedly undergoing substantial changes in the digital era. They face many challenges and have to re-evaluate their role as keepers of cultural heritage. Unlike libraries, which foreground access, archives traditionally saw themselves more as the guardians of their carefully-forged collections. Film archives, especially those with a long history of personally-oriented initiatives and activ- 
ity, have a strong tendency to work behind closed doors and only grant access to their holdings under strict conditions. While they focussed on exhibiting their film materials via curated cinema programs and exhibitions on their own premises, much more of the collection remained invisible, and the policies of international film archives towards granting access to researchers and audiences throughout the years have tended to vary.

Digitisation, whether for preservation or access, is one of the key factors in this lively debate that has been going on in recent years. Aside from the obvious advantages, such as increased visibility, the potential for fruitful collaboration with other institutions, greater possibilities for exchanging information and new forums for dissemination, there are certain obstacles and pitfalls that come with digitisation. The effect on film archives is, arguably, more painful than other archives due to the specialised nature of their collections. After lining out what the specifics are, I will suggest how digital humanities can potentially aid film archives by offering conceptual as well as practical support. A number of inspiring articles have emerged from the archival community and a lively discussion continues within official and unofficial workgroups and forums - for example, the FIAF, AMIA, ACE, Presto4You and FoFA. 'But, to this date, there are very few publications (some of which will be mentioned later) that could serve as reference works when it comes to analysing the concept of the film archive in the digital age.

\section{Prologue: digital humanities - definition of a discipline?}

One would hardly be surprised to learn that the "branding" of the term digital humanities did not occur just by chance but was a carefully considered act. In his provocative, yet nonetheless convincing article, "Digital Humanities As/ls a Tactical Term", Matthew Kirschenbaum, Associate Professor in the Department of English at the University of Maryland, ${ }^{2}$ argues that the term (at least, initially) served two primary functions:

[It] possessed enough currency and escape velocity to penetrate layers of administrative strata to get funds allocated, initiatives under way, and plans set in motion. On the other hand, it is a populist term, self-identified and self-perpetuating through the algorithmic structures of contemporary social media (Kirschenbaum, 2012, p. 417).

More than ever, the debates within the field circle around a possible definition of the discipline. It has become "something of a genre essay", writes Dave Parry (Parry, 2012, p. 429), Associate Professor and Chair of Communication and Digital Media at Saint Joseph's University, though this is not necessarily a bad thing. Indeed, it bears a certain resemblance to the still lively debates in the field of comparative literature in which open discussion is embraced by including it (at least, in Austria) in the introductory phase of the study programmes. Here, however, everything stays firmly within the humanities tradition; and, needless to say, using computer hardware or software for research does not automatically make one a digital humanities scholar. As Parry observes, the scholars in question would, 
Article: Film archives and digital humanities - an impossible match?

more often than not, describe their own work as something "in-between" and, then, proceed to name all the relevant disciplines.

\section{Traditional tasks of film archives and modern job descriptions}

Since the beginning, film archives have collected a wide range of materials, which they then normally subdivide into so-called "film" and "non-film" collections. When they use the word "film", archives usually still refer to the analogue medium in (continued) existence for over 100 years now, thousands of reels of which occupy the shelves in their storage vaults. These reels survive on different carriers (nitrate, acetate and polyester) and in different gauges (mostly $35 \mathrm{~mm}, 16 \mathrm{~mm}$ and a number of smaller formats predominantly aimed at the home market such as $9.5 \mathrm{~mm}$ or $8 \mathrm{~mm}$ ). Like the films, the non-film (or film-related) materials also have to be taken care of by specialised departments: film stills, posters, film journals, books, ephemeral ("grey") literature, film programmes, costumes, etc. Each of them requires different strategies and workflows for storage, preservation, cataloguing, presentation and digitisation. This already points to what film archives have considered their core tasks in recent decades - to collect, preserve and show.

With the digital revolution and all its implications - for example, new (file) formats, carriers and new requirements for long-term preservation, the basic functions of film archives have remained essentially the same: archives consider themselves as the keepers of the material with the mission to manage and present their holdings. ${ }^{3}$ Some of the challenges to fulfilling their expanded tasks include developing new approaches (to preservation, access, etc.), infrastructural changes and ongoing re-training of staff, but the existing guidelines and past experience can be (and are) adapted to the digital environment. The overall goal remains the same: to store the holdings in adequate places, to describe them sufficiently by adding metadata and to make sure that they can be accessed by the public in an appropriate form. With respect to these last two points about metadata and access, a major transition is under way that will shape the way (film) archives will continue to work in future.

Lately, the field of information and documentation science has been reinforced within the film archive community, both in terms of training and more substantial implementation within archival structures. Although not strictly aiming just at the staff of film archives, the University of Applied Sciences Potsdam or the Berlin School of Library and Information Sciences at Humboldt Universität zu Berlin offer specialised study programmes.

The British Film Institute (BFI) is playing a pioneering role when it comes to pushing the standardisation of metadata between film archives and granting access to its holdings online. ${ }^{4}$ In addition, the methodology and practices employed in the field of film education have been developed with the film archives and film museums as knowledgeable and logical partners. Many film archives accompany their publications with contextual material for example, video and DVD essays, audio-visual film studies, or videographic film studies; these works are informative and have their own aesthetic value as well. 
In 2009, Jeffrey Schnapp, faculty director of the metaLAB at Harvard, and Todd Presner, Professor of Germanic Languages and Comparative Literature at UCLA, described a multifaceted world in contrast to the traditional, single location of knowledge production:

The Digital Humanities seeks to play an inaugural role with respect to a world in which, no longer the sole producers, stewards, and disseminators of knowledge or culture, universities are called upon to shape natively digital models of scholarly discourse for the newly emergent public spheres of the present era (the www, the blogosphere, digital libraries, etc.), to model excellence and innovation in these domains, and to facilitate the formation of networks of knowledge production, exchange, and dissemination that are, at once, global and local (Schnapp \& Presner, 2009).

Thus, the staff of film archives are required to develop new metadata schemes better to describe their collections, which facilitate new modes of presentation (online collections) and interoperability (data exchange with other institutions). This has not been common among film archives in the past, depending on national and cultural conventions. It could be argued that the rigid division of staff according to the nature of their tasks (with technicians separated from curators) will become a little more permeable than it used to be. In addition, new roles are created within film archives for information specialists, who serve in a comprehensive and interdisciplinary function that no longer follows the old-fashioned distinctions of "analogue versus digital" or "film versus non-film".

Traditionally, archives have to fulfil a dual role: not only do they preserve and provide access to their collections (with the data being provided through online or offline databases), but they also engage with them on a content-based level. Therefore, archives - or, more generally, "collecting institutions" - often have historians, art historians or humanities scholars among their staff. Schnapp and Presner rightfully point out that a great amount of research is, indeed, carried out within libraries and archives, but it can be said that the traditional hierarchies are still very deeply rooted in people's minds (Schnapp \& Presner, 2009). Despite the fact that, even though archivists and scholars still tend to be placed in separate camps by universities, there is actually very little that separates them from what we would consider "traditional" scholars - especially, among the current generation of emerging archivists:

Given that many of today's archivists have gone through the 'traditional' academic route, and many film archives and museums themselves - as institutions - are heavily involved in academic programs if not departments in universities, it may not be an exaggeration to suggest that every archivist nowadays is a potential scholar (and every scholar a potential archivist) (Hanley \& Heftberger, 2012, p. 64).

Not only are archivists very often trained humanities scholars, they also bring to the table experience in the core areas of digital humanities - at least, if we agree with Brett Bobley, the director of the National Endowment for the Humanities' Office of Digital Humanities. 
He emphasises digitisation and the creation of online archives as important topics in which scholars should get involved:

Under the digital humanities rubric I would include topics like open access to materials, intellectual property rights, tool development, digital libraries, data mining, born-digital preservation, multimedia publication, visualization, GIS, digital reconstruction, study of impact of technology on numerous fields, technology for teaching and learning, sustainability models, media studies, and many others and humanities scholarship (Gavin \& Smith, 2012, p. 61).

One can already see how the traditional view of the archivist as the person who takes things off shelves is undergoing a radical change. This situation is particularly pertinent to audio-visual archivists because, as Martin Koerber, the Curator of Film at the Deutsche Kinemathek, puts it, they have yet to define their field as a whole:

Compared to other heritage archivists, audiovisual archivists, and audiovisual restoration experts in particular are still in a minority position. Often their demands to be accepted as heritage specialists go unappreciated by their institutions and by the heritage fields as a whole. Audiovisual archivists have yet to define their field, and due to the continuing technological change, to constantly redefine who they are and what they do will be a key challenge for the foreseeable future (Koerber, 2013, p. 46).

\section{Digital humanists and archivists - complementary or incomprehensible?}

If asked what the digital humanities have brought to the table so far, one could recall a famous line from an equally famous film: "All right, but apart from the sanitation, medicine, education, wine, public order, irrigation, roads, the fresh water system and public health, what have the Romans ever done for us?" Admittedly, this reference to "Monty Python's Life of Brian" (Terry Jones, 1979) is a tongue-in-cheek response to a very serious and valid question - but, looking at recent debates in the digital humanities, may not be an entirely inappropriate one. In this article, I draw mostly on the articles in the comprehensive publication from 2012 by the same name, Debates in the Digital Humanities. Much effort seems to go into a defence as well as a definition of the discipline. The claim by Schnapp and Presner from 2009 that "today the old theory/praxis debates no longer resonate" is, therefore, false. Not everyone welcomes the attempts to define the field nowadays. While some of the protagonists are understandably afraid of wasting their energy by participating in theoretical debates, the process is nonetheless comparable to what is going on in other disciplines such as comparative literature or media studies in which the debate itself is even integrated within university curricula.

Much of the discussion in the field concentrates on the relation between "traditional" humanities and what one could summarise in general terms as "digital literacy". Introducing computing into the humanities was a well-planned project, initiated in the US around 
2003. The call for a fundamental restructuring of knowledge centres was arguably provided by the so-called Atkins Report, issued that same year. This guiding report, informally named after Dan Atkins, W. K. Kellogg Professor of Community Informatics at the University of Michigan and the head of the commission that drafted it, was published on behalf of the National Science Foundation (NSF). It first coined the term "cyberinfrastructure", which subsequently gained popularity, thanks to two follow-up reports published in 2006 and 2007 by the NSF and the American Council of Learned Societies (ACLS), respectively. This term is generally used by US federal research funders "to describe research environments that support advanced data acquisition, data storage, data management, data integration, data mining, data visualization and other computing and information processing services distributed over the Internet beyond the scope of a single institution" (http://en.wikipedia. org/wiki/Cyberinfrastructure). The digital humanities certainly fit perfectly within this framework. Today, the vision of the NSF still reads quite ambitious:

\begin{abstract}
At the heart of the cyberinfrastructure vision is the development of a cultural community that supports peer-to-peer collaboration and new modes of education based upon broad and open access to leadership computing; data and information resources; online instruments and observatories; and visualization and collaboration services. Cyberinfrastructure enables distributed knowledge communities that collaborate and communicate across disciplines, distances and cultures (NSF, 2007, p. i).
\end{abstract}

The report essentially lists four main points on which the NSF planned to focus from 2006 to 2010: high performance computing, data analysis and visualisation, virtual organisations for distributed communities and, finally, learning and workforce development. In order to determine how the humanities and social sciences would figure in this process, the ACLS was commissioned to look into the special needs of these two disciplines. John M. Unsworth, then Dean of the Graduate School of Library and Information Science at the University of Illinois at Urbana-Champaign, acknowledged the self-reflective nature of the humanities and expressly considered them to be active and productive collaborators in the process:

After all, science - whose goal is predictive certainty - only has half the picture. Uncertainty (or ambiguity, if you prefer) is the other half, and the humanities and social sciences celebrate that, explore it, tolerate it, and understand it better than the sciences do. Or, at another level, if science and engineering are about what we can do, the humanities and social sciences are about what we should do (Unsworth, 2004).

Unsworth views the humanities as contributors that play a crucial role in solving burning social issues, and he emphasises that "the study of history, literature, languages, philosophy and other humanities subjects help us not only to better understand our own nation, but other cultures as well" (ibid.). In particular, this serves as an intelligent line of argument and also as a statement of the essential international understanding and integration through 
intercultural collaboration on which the globalised world has to rely. Unsworth points out that computational methods already hold a fixed and reasonable place within the social sciences and, if we follow up on their example, the usage of these methods might later be expanded into the research in literature, art history and history. The author takes this argument a step further by painting his vision of the ideal, universally-trained humanities scholar, who is both technologically "savvy" and possesses a profound knowledge of his own field. Only in this way, he claims, can we prevent mere product development in the research projects to come:

\footnotetext{
We will need English majors who have a background in logic, who can handle statistics, who do maths, if we are going to turn out a generation of disciplinary specialists who can bring the accumulated wisdom of the humanities to bear the computational contexts - perhaps in helping build ontologies for scholarly projects in disciplinary contexts, or building tools for data-mining in the context of humanities research (Unsworth, 2004).
}

Of course, the application of statistical methods or math is not alien to certain disciplines within the humanities, even if this is rarely brought up in the recent debate. However, I would like to focus on the role(s) of the archive and the archivist in this debate and how working in a film archive might relate to the digital humanities, especially when digitisation and Internet publications provide fascinating new areas of archival, scholarly and curatorial fields of activity. Presner and Schnapp were quite outspoken in their "Manifesto"; and, with respect to the current debate, their effort to redefine the places of knowledge creation and knowledge transfer could be considered a truly revolutionary and democratic act of bridging. While archives have often been limited to the role of information hubs, where material is merely stored for further exploration by scholars, Presner and Schnapp stood up for the archive as a much more proactive partner (Schnapp, Presner, 2009).

Inevitably, the question arises as to whether or not the lines between university scholars and curatorial professionals in archives or other research institutions have become a little blurred. So, what has been the impact of digitisation on small institutions when it comes to curation and access?

\section{Curation in film archives - engaging with collections}

Curation is regarded in the "Manifesto" as "making arguments through objects as well as words, images, and sounds" (Schnapp, Presner, 2009). Although a similar process of "spatialisation" takes place as in the humanities - especially, in history studies, the process of curation in archives is still fundamentally different. Instead of working with language as in the humanities, we work here with spaces in which physical or virtual objects are arranged in a certain way. But the potential for mutual impulses and collaboration are manifold in this transforming field: 
It means becoming engaged in collecting, assembling, sifting, structuring, and interpreting corpora. All of which is to say that we consider curation on a par with traditional narrative scholarship. It is a medium with its own distinctive language, skill sets, and complexities; a medium currently in a phase of transformation and expansion as virtual galleries, learning environments, and worlds become important features of the scholarly landscape (ibid.)

Another valid definition of curation comes from within the (film) archival field itself. Curation can, according to Paolo Cherchi Usai, Senior Curator of Motion Pictures at the George Eastman House in Rochester, be defined as "the art of interpreting the aesthetics, history, and technology of cinema through the selective collection, preservation, presentation, and documentation of films and their exhibition in archival presentations" (Cherchi Usai et al., 2008, p. 231).

Schnapp and Presner affirm that modern universities still tend to separate scholarship from curation, a fact that is hardly deniable. The latter is normally reduced to a secondary and supportive role, thus sending curators within the museums, archives and libraries into exile (see Schnapp \& Presner, 2009), while the digital humanities instead commit themselves explicitly to a new definition of the "scholar as curator and curator as scholar" (see ibid.). How does this work out in reality, and should this not also be subject to reconsideration in the traditional humanities? On the other hand, archives have to deal with different and more pressing challenges at the moment (such as digitisation and providing increased online access to their collections) than benchmarking their position.

But let's think about ways digital humanities might shape curation within film archives, which could - in short - result in a cinema programme or an online presentation. In both cases, a curator will consult sources in various forms, be it the archive's internal database, other external databases or published information on the internet. Naturally, these are not the only possibilities, and I am by no means suggesting that only online resources are of value, but it is irrelevant for the purpose of my argument. One might argue that the better the metadata structure and the better the search functions, the easier it will be to find appropriate material for the intended topic or idea. Media archives might increasingly explore different methods of computer-aided annotation by using concepts such as "smart content" ${ }^{\prime \prime}$ or crowd-sourced annotations ${ }^{6}$; others might have been added manually, following custom-developed thesauri.

Another interesting idea would be to develop algorithms as advanced curatorial tools - for example, to define certain parameters (keywords, directors, genre, and time period) and to have a computer programme come up with a list of options. While this is something that might be used by film archives for online presentations (along the lines of a "video of the month" or "you might also like this"), this form of curation will probably be met with great reservations when it comes to film programmes. Film curators - if we use the term homologously with "film programmers" - are usually defined by strong personal characteristics that set them apart from each other. Furthermore, it would be hard to define a set of parameters in which a heterogeneous choice of films can be achieved. Taking the audi- 
ence's viewpoint, Alexander Horwath, director of the Austrian Film Museum in Vienna, remarks: "For me, as a viewer, the most productive and creative programmes or 'programming calendars' are the ones that play with the energies of affirmation and subversion/ confrontation at the same time" (Cherchi Usai et al., 2008, p. 136). However, this field might be one to investigate, e.g., comparing human and computational selection or looking for patterns in curatorial decisions in order to come up with a profile of the person, the institution or distribution over time.

In addition to film programming, we can understand curation as yet another activity performed within film archives - to identify and catalogue films or photos from their collections. This task is often very slow and frustrating, sometimes even impossible, given the manpower, special knowledge and time at hand. There have been interesting initiatives in recent years to engage actively with specialists outside of one's own institution by a type of crowdsourcing for silent films such as the ambitious LOST FILMS project, initiated by the Deutsche Kinemathek in Berlin. Other initiatives include websites set up by the Danish Film Institute in Copenhagen and the National Centre for Cinema and the Moving Image (CNC) in Paris.' After much action some years ago, the proactive vibe seems to have died down lately, which might be attributed to several factors. First of all, it needs to be promoted heavily and aimed at the right audiences (we should keep in mind that we are dealing with a highly specialised film historical field); and, secondly, someone has to monitor the comments regularly, check the information received and update the archives' database, as necessary. There are other issues involved, such as how many items should be displayed and when new films/photos should be digitised and uploaded - or simply financial limitations? I think (put very simply) that, if the digital humanities could develop tools for film archives that are able to compare information online (in the form of images or texts) in a practicable way, it would help immensely to ascertain whether or not others have already uploaded the same film/photo elsewhere.

Digital tools such as the one I suggested could help collect information from diverse sources for film data, whether by specialised search functions, OCR or image recognition. In this way, the digital humanities can also support film studies in a very practical way when it comes to archival research. Typical requests from scholars often focus on identifying films in which certain images are depicted, such as cars, doors, people who smoke - to give just a few simple examples. Right now, this kind of inquiry is nigh on impossible for the film archivists to answer. Apart from drawing on personal knowledge, not much is available to them either in terms of digital tools or human resources.

Simultaneously, archives will, hopefully, put more effort into advancing the standardisation of metadata in order to be able to share and exchange filmographic information. There are signs of an increased number of joint efforts amongst some film archives in Germany (Deutsche Kinemathek and Deutsches Filminstitut) to implement the metadata standard EN 15907 with plans to collaborate with the BFI to create shared online catalogues of their holdings. Digital humanities professionals are useful for any of these processes. 


\section{No curation without digitisation - potential and pitfalls}

In a very practical sense, the aforementioned aspects of curation within film archives are limited to a certain degree by the availability of the material in digital form. While sitting on a mountain of analogue film material and non-film material, a curator is sometimes confronted with a very sobering fact: Not much of it is actually digitised - either not at all or not with a useable quality. The latter especially comes into play when a film screening is being planned. Even if prestigious archival cinemas (such as the Cinémathèque française or BFI Southbank) continue to provide venues for analogue projection, smaller organisations and festivals have gone completely digital by now. While there have always been limitations to analogue film curation as well - for example, the physical condition of the material, the amount of what can be screened digitally is, more often than not, surprisingly confined.

As the utopian ideal of unlimited digital access to archival documents becomes a reality, the role of the archives as "keepers of records" is coming under threat. Both practical and aesthetic issues arise: What access limitations are there both on a financial and a curatorial level? What possibilities are there for "non-national" archives to provide increased (digital) access to their collections while retaining a sense of tradition and identity? How can archives guide their users and make them aware of the possibilities? The fact that digitisation requires a considerable investment in terms of both financial and human resources may seem like a banal statement; nonetheless, it has significant consequences for curators. Problems concerning digital infrastructure (short- and long-term storage space options, constant migration, hardware and software upgrades) or the necessity for the continuous training and retraining of staff are the same for large and small archives alike. In conjunction with these issues, it can be claimed that there is a strong belief within the film archive community that analogue objects cannot be represented adequately in digital form if their inherent "original" characteristics are not understood. Aside from the material-philosophical implications, there is also a very pragmatic reason behind this - preparing films for digitisation requires a certain amount of expertise in the analogue realm. For film archives, curation and digitisation are closely linked; and, due to the aforementioned restrictions and obstacles, curatorial decisions are elementary for dissemination activities such as online publications or DVD editions.

The fact that, for the most part, film archives have been very reluctant in embracing the digitisation of their holdings brings more problems than solutions. While libraries were very active in building networks and funding structures for mass digitisation, film archives spent much time discussing the necessity for digitisation and whether or not it would even be possible to continue with film as an analogue carrier in the digital age. By now, taking into account recent developments in the industry - e.g. manufacturers of raw film stock stopping production of certain stocks or threatening to close down completely, the analogue film medium seems to have reached its final and ultimate end. However, there are enthusiastic initiatives to save analogue film, and many in the community have expressed the wish to continue with the medium as long as possible. ${ }^{8}$ 
Among moving image archives such as TV and media archives and film archives, the material nature of their respective collections only overlap to a certain degree. While TV archives also have many films (mostly, 16mm) on an acetate or polyester base, the bulk of their collection - for historical reasons - consists of various tape formats (or files by now). For film archives, the situation is similar but reversed. This means that, as opposed to TV and media archives, film archives have to deal with a corpus of material that is very costly and time-consuming to digitise. Furthermore, the funding structures and personnel resources of commercial TV archives are fundamentally different from film archives. Most are not even connected to governmental institutions but were established by committed individuals with a strong degree of personal involvement such as Henri Langlois, the eccentric founder of the Cinémathèque française, or Peter Kubelka and Peter Konlechner, who together founded the Austrian Film Museum. While Europe film archives usually receive at least a certain amount of financial support from the government, American archives generally have to rely to a great extent on grant applications and donations, which makes the planning of special projects such as mass digitisation very difficult.

TV or media archives have also gained far more experience and know-how over the years when it comes to format migration and storage. This is due to more frequent advances in broadcast technology and the need to represent "the state of the art". Other factors include the precarious nature of tape-based audio and video formats as well as lower demands when it comes to quality (standard definition analogue video can be transferred much easier to digital than film). Film archives, on the other hand, still see themselves very often as preservers of the cultural heritage rather than institutions that have to react quickly to a changing environment. But even if a film archive fully embraces the digital revolution and is well funded, it usually still struggles with the sheer size of the analogue backlog.

Compared to the relatively low costs of digitising and storing paper and photos, the costs of digitising film materials are significantly higher. This becomes clearer if we look at film as a series of photographs, all of which have to be scanned at a suitably high resolution to be projected on the big screen. If, for example, we wanted to digitise a relatively short silent film with a run time of 60 minutes, which would be screened at 16 frames per second and survives on $35 \mathrm{~mm}$ nitrate film, we would be talking about scanning somewhere in the vicinity of 57,600 individual film frames. The amount of storage space that would have to be reserved for the raw scans in $2 \mathrm{~K}$ resolution already adds up to $691 \mathrm{~GB}$, while scans in $4 \mathrm{~K}$ resolution (increasingly becoming the required standard) would call for $2.76 \mathrm{~TB}$ of storage space - all for just one film. This calculation is meant as a much simplified example and omits all the details involved. I intend merely to provide a rough idea of how much storage space might be needed. Even if the raw scans are compressed before being worked on, it is still considered standard practise in archives to keep the raw data together with any new "products". Moreover, when we enter the realm of digital restoration - a very common reason for digitising film material, we have to take into account that not only is the final version normally kept but also all the different stages of manipulation. It goes without saying 
that the administration of such complex processes as these demand elaborate metadata schemes within the digital archive as well as proper links to the analogue sources.

Mass digitisation of analogue film material - whether for preservation or for access - is still not a viable option for film archives even if additional funding happens to be available. One important reason for this is that, even if the prices for high quality digitisation were to drop significantly in coming years, the available funding will still not cover even a small number of full feature films or even a reasonably large number of short films. Of course, it is also possible to digitise at a lower quality for ease of access, but this seems a very shortsighted approach given that it practically limits use of the material to online presentation. Any use of the material beyond that where a higher quality is required would essentially mean having to repeat the same work again in future. Another aspect is the ever-growing multitude of different file formats, all of which demand diverse strategies and workflows. It should also not be forgotten that the films prioritised for digitisation (usually, the oldest) very often survive only on nitrate film stock and are rarely in a state that allows fast and easy digitisation, due to age (fragility) and damage as a result of rough handling over the years. Films such as these normally have to be repaired and cleaned - both very costly procedures that can only be carried out by specialised people and laboratories.

But even if an archive succeeds in getting a considerable part of their collection digitised, the problems continue. Film archives cannot simply switch from analogue to digital but, rather, have to keep both systems in operation. Opinion is still divided on the long-term costs involved in digitisation and whether or not it can be considered less expensive than traditional analogue preservation. ${ }^{9}$ Financial support for digitisation usually does not cover the set-up costs or the running costs of a digital archive on hard drives or servers plus longterm storage (for example, on LTO tapes). As mentioned previously, these radical changes to the traditional workflow call for technical support in various new areas. On top of that, it also means a complete restructuring of metadata systems and existing archival databases. Not many institutions will be able to establish an information department like the BFI with skilled information specialists - we might also call them digital humanists (although they probably would not refer to themselves this way) who deal with these important issues in an intelligent and sensible way.

One final related issue should also be mentioned: When it comes to selecting films for digitisation, it certainly does not make sense for two or more archives unwittingly to digitise the exact same films at the same time. The fact that film archives frequently hold prints or duplicates of the same films is due to the historical circumstances of film distribution. Film has always been an international medium and was intended to circulate throughout the globe; therefore, one should not be taken completely by surprise when an uncut version of a famous German film such as "Metropolis" (Fritz Lang, 1927) appears in South America. As a side note, this "internationality" of film has had negative consequences for film archives when it comes to obtaining local or national funding for digitisation since many of the films held by the local film archives may not necessarily pertain to local productions. In other 
words, how can we make sure the same material is not being digitised twice in different countries or institutions? One reasonable answer would be: By exchanging as much information as possible by using efficient tools for data exchange and interoperability.

One question we might like to ask ourselves is: at what point will students actually acquire the desired technical and conceptual skills? Surely, in the end, they can only come from extensive practical exercise. Most universities cannot offer that unless it is part of the curriculum and, even then, can hardly provide the routine practice necessary for acquiring said skills. So, where should students go to learn such diverse skills as databasing, programming, the digitisation of various objects or text-mining? The need for training has barely been discussed in recent articles. One can only speculate as to why. Is it that, in American digital humanities centres, technical training is provided anyway since it is included as part of the programme? Or do many scholars subconsciously tend to attribute less significance to these "science tools" in the humanities (and the digital humanities) because, unfortunately, they still consider them to be too practice-oriented. For many in the field, it would suffice to understand computer software only to a certain (primarily, theoretical) extent in order to conduct research on a meta-level. Lev Manovich, the founder and director of the Software Studies Initiative in San Diego, is among the few voices advocating the necessity of training. He writes:

The model of big-data humanities research that exists now is that of collaboration between humanists and computer scientists. It is the right way to start "digging into data". However, if each data-intensive project done in the humanities would have to be supported by a research grant, which would allow such collaboration, our progress will be very slow. We want humanists to be able to use data analysis and visualization software in their daily work, so they can combine quantitative and qualitative approaches in all their work. How to make this happen is one of the key questions for the digital humanities (Manovich, 2012, p. 473).

Furthermore, it appears that those who make the decisions concerning the allocation of research grants share Manovich's opinion. In an interview held in 2009, Brett Bobley shares his thoughts on this topic:

One issue l'd like to see graduate programs tackle: more training in digital tools and methodologies for humanities scholarship. [...] How many graduate humanities programs include classes on using GIS, 3-D modelling, data analysis, or other methods of scholarship? (Gavin \& Smith, 2012, p. 65).

Although mass digitisation is not likely to happen in the near future, film archives will strive to digitise for various purposes. Considering the rising costs involved, the need to hire additional personnel trained in more than one area, and changing storage solutions and file systems, the need for useful guidelines to make sensible decisions becomes clear, something digital humanities might become more actively engaged in. 


\section{European projects, funding opportunities for digitisation and mining the collections}

The European Film Gateway project (Sept. 2008 to Aug. 2011), ${ }^{10}$ co-coordinated by the Deutsches Filminstitut, and its follow-up project EFG1914 (Feb. 2012 to Feb. 2014) were set up to facilitate the high-quality digital transfer of analogue film material and to present it on a web portal. Looking at the current EU funding opportunities presented at the annual meeting of the EU Commission's "Film Heritage Expert Group" in Brussels in November 2013, no further film digitisation projects will be supported - at least, not before 2020.

It may look as though there are many European-funded projects around such as, for example, EUscreen, but one has to look very carefully at whether they are really being set up to facilitate digitisation and not just online access. This might be a strong signal that the EU considers digitisation primarily a national issue. And, actually, some countries are more active than others in providing financial support for the digitisation of their film heritage. However, there are huge differences in the amounts of money governments are willing to give: While in France the CNC received 400 million Euros for digitisation in 2011, the major film institutions in Germany have had to make do with only 1 million Euros between them. As Martin Koerber points out, the 200,000 Euros his institution, the Deutsche Kinemathek, will get can only facilitate the digitisation of up to a maximum of ten films, providing that no extensive restoration work has to be performed (Koeber 2014). Other examples may be found in Sweden and Finland, where the archives actively acquired national funding to digitise films from their collections.

While this model may seem to work fine for some national archives at the moment, there are crucial disadvantages to a purely national approach, the most radical one being that funding might be cut quite abruptly when the government changes, as we have seen with the project "Images for the Future" in the Netherlands. ${ }^{11}$ From a more general point of view, it can be argued that passing the responsibility for film digitisation over to the individual countries restricts the creation of standardised workflows as well as synergies among the different institutions and information networks.

The European Union's point of view can also be interpreted as the prioritisation of contextualisation and enrichment of online content accessible on Europeana rather than encouraging increased digitisation by providing the necessary funding. It is further aimed at trying to involve teachers and facilitate the use of available online content in the teaching framework. The conference "Unlocking the Sources - The First World War Online \& Europeana" on January 30/31 may serve as a good example to see how this process is being encouraged in the various areas. In many presentations, the focus was on how First World War-related material in the Europeana collections, among other sources, has been used in a number of international projects. Some talks also tackled the issue of how best to search and find what is needed. It soon became clear that we are still in the early stages of trying to cope with the thousands of objects digitised in a useful way. There have been criti- 
cal remarks that the tools offered are not yet sufficient - especially, the search functions, which still have their shortcomings in full-text search and documents in languages other than English. In the context of this article, the lecture given by Jörg Lehmann, currently a postdoctoral research fellow at the University of Stuttgart, is worth mentioning. Lehmann talked about the Europeana collections from the perspective of the concept of "distant reading":

Mass digitization provides several challenges for philologists who have concentrated so far on the close reading of a few canonical texts. What can be meaningful questions directed at a corpus as big as the literary texts and wartime memoirs provided by Europeana Collections 1914-1918? What methods can currently be used for the analysis of several hundred texts?

With the introduction of ideas such as "distant reading" or "computer reading", a highly privileged concept in the traditional humanities is coming under threat - namely, the act of "reading". The American literary scholar and Director of Graduate Studies in the Program in Literature at Duke University, N. Katherine Hayles describes the two different "philosophical commitments" as follows:

At one end of the spectrum, 'reading' in the traditional humanities connotes sophisticated interpretation achieved through long years of scholarly study and immersion in primary texts. At the other end of the spectrum, 'reading' implies a model that eschews human interpretation for algorithms employing a minimum of assumptions about what results will prove interesting or important (Hayles, 2012, p. 47).

This means that not only what or how much we read but also how we read is fundamentally reconsidered. Certainly, the debate is still open as to whether the attempt to read an artwork "quantitatively" can be seen as highly questionable and unacceptable. Indeed, it could be seen more closely to resemble a suspicious form of "measuring" rather than reading. It is enlightening to take a look at the discussion surrounding Franco Moretti's influential publication, "Maps, Graphs and Trees", in which he presents his highly-debated method of "distant reading" as opposed to the more traditional form of "close reading" (to which one may add: only of canonical works). The Italian-born scholar is currently Danily C. and Laura Louise Bell Professor and Professor of Comparative Literature at Stanford University. Despite heavy resistance, Moretti has found some supporters, such as the Assistant Professor of Philosophy at the National University of Singapore John Holbo. Holbo, in suitably snappy words, sums up the situation as follows: "If the answer is that literary scholars take the undesirability of quantification for granted, whereas everyone else takes its desirability for granted, the literary folks are flat out of luck" (Holbo, 2011, p. 9).

On the one hand, this step towards a historical and also explorative form of engagement with online material for and by the public as well as scholars is highly appreciated and welcomed by the film archive community. On the other hand, it still leaves them with 
the pressing problem of how to make their holdings available for future generations online, especially when their budgets remain what they were in older, pre-digital times.

As is commonly known and as the wording suggests, smaller film archives have to suffice with a lack of financial and human resources. At times, these economic restrictions have had an influence on shaping individual collection policies. Other curatorial questions such as what, where and how to publish are also connected to economic restrictions but are more strongly linked to the archive's (not completely unfounded) fear of seeing their content disappear in the vast void of the Internet. One way to approach online curation, which is practised in the Austrian Film Museum, is to select content according to the institution's self-image, to investigate what is special about it and what constitutes it at its core. Online curation, in this view, can be seen as a means to highlight special collections or representative parts of the collection. Moreover, curation bears the notion of responsibility towards the original artefact, such as ensuring analogue film materials are presented in the cinema in their original formats $(16 \mathrm{~mm}$ and $35 \mathrm{~mm}$ prints) or guaranteeing a suitable technical standard for the online presentation. The Kinonedelja (Kino-Week) newsreels represent Dziga Vertov's first contribution to cinema and were the first moving images published on the Film Museum's website in May 2012.12

\begin{tabular}{|c|c|}
\hline Film Collection & Kinonedelja - Online Edition \\
\hline Stills Collection & e Kinonedelja (Kino-Week) newsreels rep \\
\hline Ephemeral Paper and & to cinema. A total of 43 issues, each containing an average of 5 to 7 different \\
\hline Documents Collection & items, were produced between May 1918 and June 1919. Vertov joined the \\
\hline Periodicals Collection & $\begin{array}{l}\text { newsreel's ranks as a secretary initially but by the fall of } 1918 \text { had taken on full } \\
\text { responsibility for the series. The Austrian Film Museum holds prints of } 14 \text { clearly }\end{array}$ \\
\hline Dziga Vertov Collection & identifiable issues of the Kinonedelja series. The films provide an invaluable \\
\hline Objective & $\begin{array}{l}\text { record of life in the young Soviet Russia, then in the throes of civil war. Within the } \\
\text { framework of the EFG1914 project, and continuing its recent tradition of publishing }\end{array}$ \\
\hline Online Search & important works by Dziga Vertov in digital form, the Film Museum has made its \\
\hline Films: Overview & complete Kinonedelja holdings freely available online. The publication of the \\
\hline $\begin{array}{l}\text { Kinonedelja - Online } \\
\text { Edition }\end{array}$ & $\begin{array}{l}\text { Kinonedelja - Online Edition marks the first presentation of moving images on the } \\
\text { Film Museum's website. For the online presentation, the Viennese collection is } \\
\text { complemented by additional digitized Kinonedelja issues and fragments held by }\end{array}$ \\
\hline Amos Vogel Library & $\begin{array}{l}\text { the Danish Film Institute in Copenhagen and the Swedish Film Institute in } \\
\text { Stockholm. }\end{array}$ \\
\hline Schlemmer Frame Collection & Read more about the Kinonedellia series \\
\hline Technical Apparatus & View related documents \\
\hline
\end{tabular}

Library
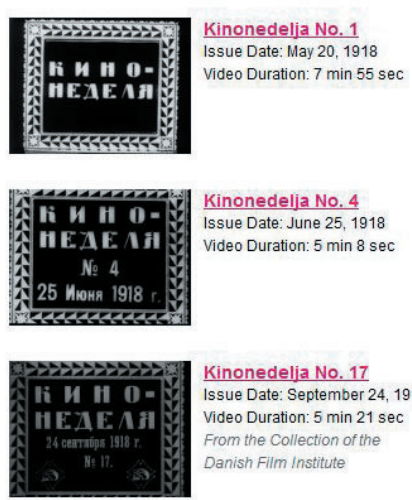

Kinonedelja No. 4 Issue Date: June 25,1918
Video Duration: 5 min $8 \mathrm{sec}$

Kinonedelja No. 17 Issue Date: September 24, 1918 Video Duration: $5 \mathrm{~min} 21 \mathrm{sec}$ From the collection of the Danish Film Institute

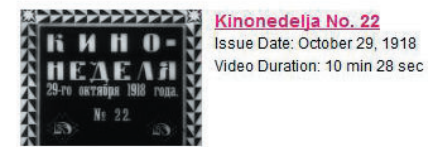

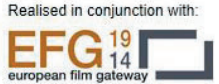

Thanks to:

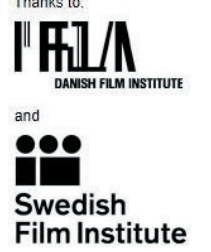

Kinonedelja No. 3 Issue Date: June 15, 1918 Video Duration: $8 \mathrm{~min} 51 \mathrm{sec}$
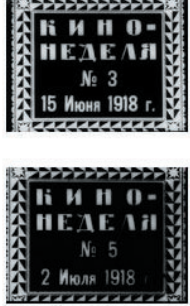

Kinonedelja No. 5 Issue Date: July 2, 1918 Video Duration: $5 \mathrm{~min} 46 \mathrm{sec}$

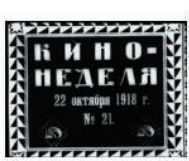

Kinonedelja No. 21 Issue Date: October 22 1918 Video Duration: $7 \mathrm{~min} 39 \mathrm{sec}$

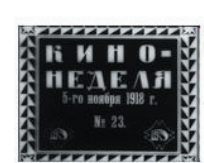

Kinonedelja No. 23

. November 5, 1918 Video Duration: $6 \mathrm{~min} 9 \mathrm{sec}$ 
I think one could safely position publications such as the Kinondelja - Online Edition or recent digitisation projects in film archives within the framework of the digital humanities, even though they are not always acknowledged as such by academics and are often reduced to a mere service function. The act of presenting archival collections online is not far from the notion of "creating" or "building", as advocated by the quite outspoken Stephen Ramsey, Susan J. Rosowski Associate University Professor of English at the University of Nebraska-Lincoln:

I think Digital Humanities is about building things...If you are not building anything, you are not... a digital humanist. You might be something else that is good and worthy - maybe you're a scholar of new media, or maybe a game theorist, or maybe a classicist with a blog (the latter being very good thing indeed) — but if you aren't building, you are not engaged in the 'methodologization' of the humanities, which, to me, is the hallmark of the discipline that was already decades old when I came to it (Ramsey, 2011).

Although Schnapp and Presner have provided many insightful and "revolutionary" thoughts concerning a new definition of the relation between the universities and other institutions within the knowledge world (such as archives and libraries), there is certainly room for improvement. Likewise, the initial "Manifesto" was democratic in suggesting an attempt to break up traditional hierarchies by, for example, incorporating independent scholars who work outside an academic infrastructure. Recent debates in the digital humanities seem, however, to be reduced to discussing new ways of publishing scholarly articles or to demarcations within the field (traditional versus digital humanities) and prolonging the familiar debate of quantitative analysis versus hermeneutical tradition.

\section{References}

Atkins, Dan (2003). Revolutionizing Science and Engineering through Cyberinfrastructure: Report of the National Science Foundation Blue-Ribbon Advisory Panel on Cyberinfrastructure. January. Retrieved August 10, 2014, from https://arizona.openrepository.com/arizona/bitstream/10150/106224/1/report. pdf.

Berry, David (Ed.) (2012). Introduction. Understanding the Digital Humanities. In David Berry (Ed.), Understanding Digital Humanities (pp. 1-20). Basingstoke: Palgrave Macmillan.

Cherchi Usai, Paolo; Francis, David; Horwath, Alexander; Loebenstein, Michael (Eds.) (2008). Film Curatorship. Archives, Museums, and the Digital Marketplace. Wien: FilmmuseumSynemaPublikationen.

Gavin, Michael; Smith, Kathleen Marie (2012). An Interview with Brett Bobley. In Matthew K. Gold (Ed.), Debates in the Digital Humanities (pp. 61-66). Minnesota, London: University of Minnesota Press.

Hanley, Oliver; Heftberger, Adelheid. Scholarly Archivists/Archival Scholars: Rethinking the Traditional Models. The Velvet Light Trap, 70, Fall 2012.

Hayles, N. Katherine (2012). How We Think: Transforming Power and Digital Technologies. In David Berry (Ed.), Understanding Digital Humanities (pp. 42-66). Basingstoke: Palgrave Macmillan.

Kirschenbaum, Matthew (2012). Digital Humanities As/Is a Tactical Term. In Matthew K. Gold (Ed.), Debates in the Digital Humanities (pp. 415-428). Minnesota, London: University of Minnesota Press. 
Koerber, Martin (2013). "Who Are These New Archivists?". In Kerstin Parth, Oliver Hanley, Thomas Ballhausen (Eds.), Work/s in Progress. Digital Film Restoration Within Archives (pp. 43-50). Vienna: SYNEMAPublikationen.

Koerber, Martin (2014). "Archive ohne Archivare sind ein Witz". Retrieved August 10, 2014, from http:// filmerbe-in-gefahr.de/page.php?1,710,0,.

Manovich, Lev (2012). Trending: The Promises and the Challenges of Big Social Data. In Matthew K. Gold (Ed.), Debates in the Digital Humanities (pp. 460-475). Minnesota, London: University of Minnesota Press.

National Science Foundation (2007). Cyberinfrastructure Vision for 21st Century Discovery. Retrieved August 10, 2014, from http://www.nsf.gov/pubs/2007/nsf0728/index.jsp?org=EEC.

Parry, Dave (2012). The Digital Humanities or a Digital Humanism. In Matthew K. Gold (Ed.), Debates in the Digital Humanities (pp. 429-437). Minnesota, London: University of Minnesota Press.

Ramsey, Stephen (2011). Who's In and Who's Out. Retrieved August 10, 2014, from http://stephenramsay. us/text/2011/01/08/whos-in-and-whos-out/?utm_source=feed\&utm_medium=rss \&utm_campaign= interessante-links-week-36.

Schnapp, Jeffrey; Presner, Todd (2009). Digital Humanities Manifesto 2.0. Retrieved August 10, 2014, from humanitiesblast.com/manifesto/Manifesto_V2.pdf.

Unsworth, John M. (2004). Cyberinfrastructure for the Humanities and Social Sciences. Retrieved August 10, 2014, from http://people.brandeis.edu/ unsworth/Cyberinfrastructure.RLG.html.

\section{Notes}

1 Fédération Internationale des Archives du Film (FIAF), Association of Moving Image Archivists (AMIA), Association des Cinémathèques Européennes (ACE) and Future of Film Archives (FoFA).

2 Furthermore, he holds the position as Associate Director of the Maryland Institute for Technology in the Humanities (MITH).

3 This opinion is not shared by everyone within the field but is expressed more poignantly by Martin Koerber in an interview about film archives in times of transition from analogue to digital, see here: http://www.goethe.de/ins/fr/lp/kul/mag/flm/de10740851.htm.

4 To search the BFI's database online, see here: http://collections-search.bfi.org.uk/web.

5 As one interesting example, see the website by the Austrian research institution "Salzburg research": http://de.slideshare.net/snml/smarte-annotationen-ein-beitrag-zur-evaluation-von-empfehlungen-frannotationen.

6 See, for example, the project by the EYE Film Institute Netherlands: http://www.archimuse.com/ mw2010/papers/oomen/oomen.html.

7 For information on the Danish Film Institute, see here: http://www.dfi.dk/Filmhuset/Filmarkivet/Identificer-en-film.aspx; for information on the CNC initiative, see here: http://www.cnc-aff.fr/internet_cnc/ Internet/ARemplir/Aidelnconnu.aspx?Menu=MNU_AIDEID\#film10; and for another project by the Hungarian Film Archive (MaNDA), see here: http://www.filmarchiv.hu/admin/azonositatlan/index.php.

8 The British artist Tacita Dean, together with the Mexican cameraman Guillermo Navarro, has founded the initiative "Save Film"; for more information, see here: http://www.savefilm.org/.

9 See, for example, the report "The Digital Dilemma", published by the Academy Film Archive (http:// www.oscars.org/science-technology/council/projects/digitaldilemma/) or the discussion carried on amongst moving image specialists on the website "Filmerbe in Gefahr" (http://filmerbe-in-gefahr.de/ page.php?1,710,0,).

10 Additional information can be found on the website: www.europeanfilmgateway.eu. 
Article: Film archives and digital humanities - an impossible match?

11 For information, see here: http://www.beeldenvoordetoekomst.nl/.

12 The videos can be viewed here: www.filmmuseum.at/en/collections/dziga_vertov_collection/kinonedelja_online_edition.

Adelheid Heftberger, DPhil

Curator/Researcher

Austrian Film Museum, Vienna

a.heftberger@filmmuseum.at 